\title{
Effect of PA-MSAH preprocessing on the expression of TLR-4-NF- $\kappa$ B pathway and inflammatory factors in the intestinal tract of rats with septic shock
}

\author{
WENHAO ZHANG* ${ }^{*}$ JIAKUI SUN ${ }^{*}$, XIAO SHEN, YINYING XUE, SHOUTAO YUAN and XIANG WANG \\ Department of Critical Care Medicine, Nanjing First Hospital, \\ Nanjing Medical University, Nanjing, Jiangsu 210006, P.R. China
}

Received May 30, 2018; Accepted January 28, 2019

DOI: $10.3892 /$ etm.2019.7247

\begin{abstract}
Effects of Pseudomona blank s aeruginosa-mannose sensitive hemagglutini (PA-MSHA) preprocessing on toll like receptor (TLR)-4-NF- $\mathrm{B}$ pathway and inflammatory factors expression in the intestinal tract of rats with septic shock were investigated. A total of 30 rats were randomly divided into 3 groups $(n=10)$ : Blank control, septic shock, and PA-septic shock group. After the model was successfully established, the average arterial pressure in rats was monitored. The concentration of cytokine interleukin-1 (IL-1), IL-6 and tumor necrosis factor- $\alpha$ (TNF- $\alpha$ ) were determined by ELISA method. Flow cytometry was performed to detect TLR-4 expression. Number of in vitro chemotaxised neutrophils was detected by Transwell chamber. The expression of TLR-4, NF- $\kappa \mathrm{B}$ and ICAM-1 and VCAM-1 was detected by western blot analysis. The concentration of cytokine IL-1, IL- 6 , TNF- $\alpha$ in the peritoneal lavage fluid and the intestinal tissue significantly increased in the septic shock group and the PA-septic shock group $(\mathrm{P}<0.05)$, and the concentration in the PA-septic shock group was significantly lower than that of the septic shock group $(\mathrm{P}<0.05)$. Compared to the control group, the expression of TLR-4, NF- $\kappa$ B and ICAM-1 and VCAM-1 increased in the septic shock and PA-septic shock group $(\mathrm{P}<0.05)$, and the expression level of PA-septic shock group was lower than the septic shock group $(\mathrm{P}<0.05)$. The expression of TLR-4 in the PA-septic shock group was lower than the septic shock group $(\mathrm{P}<0.05)$. PA-MSHA pretreatment reduced inflammation, thus preventing the intestinal injury caused by septic shock.
\end{abstract}

Correspondence to: Dr Xiang Wang, Department of Critical Care Medicine, Nanjing First Hospital, Nanjing Medical University, 68 Changle Road, Nanjing, Jiangsu 210006, P.R. China

E-mail: vpaph041@163.com

*Contributed equally

Key words: septic shock, pseudomonas aeruginosa-mannose sensitive hemagglutin, intercellular adhesion molecule-1, toll-like receptor 4

\section{Introduction}

Septic shock is caused by the immerse release of inflammatory mediators or cytokines triggered by pathogens and their released toxin products, which further leads to increased vascular dilatation and capillary permeability as well as hypovolemia induced insufficiency of tissue perfusion, thereby leading to sepsis syndrome associated with shock (1). It has been reported that septic shock is caused by excessive stimulation of the immune system by bacterial toxins, resulting in excessive proinflammatory cytokine production, including tumor necrosis factor- $\alpha$ (TNF- $\alpha$ ), interleukin-1 (IL-1) and IL-6 (2). In the United States, there are approximately 750,000 patients with septic shock each year and nearly 250,000 of them will die (3). Although kinds of advanced methods have been applied to the treatment of septic shock, few have been able to bring down the high mortality rate of septic shock. In the intensive care unit (ICU), the in-hospital mortality rate of the patients with systemic septic shock is $29 \%$ (4), and the 30 day mortality rate is up to $54 \%$ (5).

When serious microbial infection or extensive tissue damage occurs, alarmin proteins released from necrotic cells, together with pathogen associated molecular patterns (PAMPs) expressed by nonpathogenic bacteria, are collectively referred to as damage associated molecular patterns (DAMPs). High concentration of DAMPs will lead to a comprehensive, systematic immune response (both innate and adaptive immunity are involved), resulting in inflammatory cascade (6). Specifically, neutrophils, macrophages and other immune cells produce and release a large number of cytokines (such as IL-1, IL-6 and TNF- $\alpha$ ), chemotactic factors, complement activated products and other mediators. This proinflammatory environment can lead to more powerful release of secondary medium (such as lipid factors and active oxygen). Due to the excessive stimulation of immune cells, the body produces many abnormal cytokines (called cytokine storm), which results in the excessive expression of the beneficial anti-infection response as well as occurrence of destructive inflammation (7).

Studies have shown that during the progression from sepsis to septic shock, immunosuppression (including the complete shutdown of important intracellular signaling pathways and acquired immune dysfunction) is an important cause of sepsis 
exacerbation and even death (8). It is worth noting that in sepsis, neutrophils may have 'paralysis of the immune function' (9). As important effector cells of innate immunity, neutrophils was the first responder that migrate to infection site at early stages of infection. Neutrophils roll along and adhere to the endothelial cells, which was mediated by selectin, immunoglobulin superfamily and integrin molecules (10). Once transpassing endothelial membrane, neutrophils was guided by chemokines to move along the gradient towards the inflammatory site (11), and finally kill pathogenic bacteria by phagocytosis and release of hyperoxide and protease. It can be seen that the normal migration of inflammatory cells to inflammatory sites is an important prerequisite for anti-infection response.

Septic shock is the result of the host's immune response to the pathogen. Different pathogen patterns were identified by pattern recognition receptor family the toll-like receptors (TLR). Different types of TLR are responsible for different pathogen groups. For instance, TLR-4 is the main transmembrane receptor for the transduction of G- bacterial endotoxin (LPS) signal. Once TLR-4 recognizes LPS, it initiates the immune process, and increases the TREM-1 expression (12) that can enhance the cytokine cascade after infection, hence it plays a core role in the occurrence and development of sepsis $(13,14)$.

Pseudomonas aeruginosa-mannose sensitive hemagglutinin (PA-MSHA) is a biologic drug that has the function of bidirectional immunomodulation and killing tumor cells, which has been widely used in tumor adjuvant therapy $(15,16)$. The mechanism of PA-MSHA participating in the anti-infection process has also become a research hot spot in recent years. Recent studies have found that PA-MSHA is the natural ligand of TLR-4 $(17,18)$, which can increase the proportion of CD4 ${ }^{+}$ $\mathrm{CD}_{25}{ }^{+} \mathrm{Foxp}^{+}$regulatory $\mathrm{T}$ cells (Treg) in peripheral blood cells, thereby regulating immune response $(19,20)$. Therefore, we speculate that PA-MSHA may play a role in regulating tissue immunity and inflammation in septic shock.

In this experiment, PA-MSHA pretreatment was administered to the rat model of septic shock. The expression of ascite cytokines, intestinal mucosal cytokines, adhesion molecule and peripheral blood neutrophils TLR4 was observed. The preventive effect of PA-MSHA on infective intestinal injury is discussed. Our study will offer novel therapeutic strategies in septic shock treatments.

\section{Materials and methods}

Animals and grouping. SPF male SD rats (aged 8-10 weeks), weighing 240-260 g, were randomly divided into 3 groups $(n=10)$, the blank control, the septic shock and the PA-septic shock group. Rats were housed in a temperature controlled room $\left(21 \pm 2^{\circ} \mathrm{C}\right)$ with a relative humidity range from 30 to $40 \%$ on a $12: 12 \mathrm{~h} \mathrm{light/dark} \mathrm{cycle} \mathrm{(lights} \mathrm{on} \mathrm{at} 06: 00$ ). All rats had free access to water and food. Each rat of blank control group was injected subcutaneously with normal saline, $0.3 \mathrm{ml} /$ day for 7 days. The septic shock group was given $0.3 \mathrm{ml} /$ day by subcutaneous injection of saline injection for 7 days. In PA-septic shock group, PA-MSHA was injected subcutaneously at $0.3 \mathrm{ml} /$ day. After continuous administration for 7 days, the rat model of septic shock was established by replicating the CLP model at day 8. After $14.5 \mathrm{~h}$, mean arterial pressure (MAP) of rats were monitored every $30 \mathrm{~min}$. In this study, when the MAP of rats was reduced to $70 \%$ or below (excluding low blood pressure caused by other causes such as massive bleeding), it was considered that the septic shock model preparation succeeded.

This study was approved by the Animal Ethics Committee of Nanjing First Hospital, Nanjing Medical University Animal Center (Nanjing, China).

\section{Specimen collecting and testing}

Peritoneal lavage and bacterial culture. After being anesthetized, the rats were placed in supine position on the sterile operation table. Conventional surgery area disinfection was conducted. Then incision of the neck skin along the midline was performed, and the right common carotid artery was separated layer by layer. After the puncture needle was fixed, the monitor was connected to monitor the vital signs. The abdominal cavity was opened, and RPMI-1640 culture fluid was used to lavage the abdominal cavity with $5 \mathrm{ml} / \mathrm{times}$ 4 times. The irrigation solution was then pipetted into two $10-\mathrm{ml}$ centrifuge tubes (the recovery rate is $>80 \%$, which is defined as the effective recovery of more than $16 \mathrm{ml}$ ). The two $10-\mathrm{ml}$ centrifuge tubes were separated into tube 1 and 2 . Tube 1 was centrifuged at $1,500 \mathrm{x} \mathrm{g}$ for $5 \mathrm{~min}$ at $20^{\circ} \mathrm{C}$ and the supernatant was sub-packed into $2 \mathrm{ml}$ EP tubes, preserved at $-60^{\circ} \mathrm{C}$ in a refrigerator. The irrigation solution in tube 2 was used for bacterial culture.

Abdominal aorta blood sampling. Obtained blood ( $3 \mathrm{ml})$ was injected into the blood culture bottle for blood culture. The residual arterial blood was added to $4.5 \%$ EDTA anticoagulant for neutrophils isolation.

Peripheral blood neutrophils isolation. Anticoagulant and 2\% Dextran solution was mixed at 1:1 volume, gently whirl mixed and left static for $1 \mathrm{~h}$. The white blood cell suspension in the transparent supernatant was then collected and pipetted into another tube. After $10 \mathrm{~min}$ of centrifugation at $1,500 \mathrm{x} \mathrm{g}$ at $20^{\circ} \mathrm{C}$, the supernatant was discarded, $5 \mathrm{ml} 0.1 \%$ EDTA liquid was added to the white cells of test tube wall. A total of $1.5 \mathrm{ml}$ $0.1 \%$ EDTA liquid was added to washing and discarded supernatant to make the suspended white cell suspension in another tube. A total of $2 \mathrm{ml} 75 \%$ Percoll separation liquid was added, followed by addition of $2 \mathrm{ml} \mathrm{60 \%} \mathrm{Percoll} \mathrm{separation} \mathrm{liquid.}$ Percoll stratification with different densities was observed by the naked eye. The suspended white cell suspension was gently laid on the $60 \%$ Percoll separation liquid and placed in a horizontal hanging basket centrifuge. The cloud layer cells were fully absorbed by the PAP suction tube, and the centrifuge tube was placed in the tube, and the $0.1 \%$ EDTA liquid was centrifuged at $1,500 \mathrm{x}$ g for $3 \mathrm{~min}$ at $20^{\circ} \mathrm{C}$ with $6 \mathrm{ml}$ 2 times. After centrifugation, the neutrophils were washed and resuspended with $1 \mathrm{ml}$ buffer.

Flow cytometry. Human TruStain $\mathrm{FcX}^{\mathrm{TM}}$ (cat. no. 422301; BioLegend, San Diego, CA, USA), used as the blocking solution, was added for incubation at room temperature for $5 \mathrm{~min}$. The neutrophil suspension was divided into 2 test tubes, TLR-4 and IgG tube. A total of $2 \mu \mathrm{l}$ anti-TLR4 antibody 
(ab45104; Abcam, Cambridge, MA, USA) was added into the TLR-4 tube, and $2 \mu 1$ mouse IgG2b-isotype control (ab91532; Abcam) added into IgG tube. Goat anti-mouse IgG $(\mathrm{H}+\mathrm{L})$ Cross-Adsorbed secondary antibody (FITC) (cat. no. 31541) was purchased from Thermo Fisher Scientific, Inc., (Waltham, MA, USA) and incubated at $20^{\circ} \mathrm{C}$ for $30 \mathrm{~min}$. Both tubes were incubated in the dark for $30 \mathrm{~min}$ at room temperature. The samples were washed in phosphate-buffered saline (PBS) 3 times and measurements were performed by a flow cytometer (FACSCalibur; BD Biosciences, San Jose, CA, USA). Data were obtained and analyzed using the CellQuest professional software (BD Biosciences)

Transwell chamber method. The neutrophils were diluted and isolated with the buffer solution, and the cell density was adjusted to $1 \times 10^{6} / \mathrm{ml}$. The chemotactic solution was prepared by fMLP and buffer solution at $10^{-4} \mathrm{M}$. A total of $600 \mu \mathrm{l}$ fMLP chemotaxis solution or buffer solution was added into the lower chamber of culture plate. The upper chamber of Transwell chamber was placed into the culture plate with $100 \mu$ l diluted neutrophils injected into the Transwell chamber. The Transwell chamber was placed at $37^{\circ} \mathrm{C} 5 \% \mathrm{CO}_{2}$ incubator and incubated for $60 \mathrm{~min}$. Finally, the Transwell chamber was taken out of the incubator to terminate the chemotaxis, then fixed for $3 \mathrm{~min}$ in methanol, stained with Wright-Giemsa staining. Stained cells were counted and photographed by microscopy.

Exploratory laparotomy and specimen collection. Exploratory laparotomy was conducted to observe the color and shape of the intestine. Jejunum tissue $(4 \mathrm{~cm})$ was removed at $10 \mathrm{~cm}$ away from the distal end to $10 \mathrm{~cm}$ of pileus ventriculi. The tissue was repeatedly washed with normal saline. Blood, feces and intestinal juice from internal and external side of intestinal canal were washed away. The tissue was put into the aseptic cryopreservation tube, then immediately stored in the liquid nitrogen for preservation.

Detection of $I L-1 \beta, I L-6$ and $T N F-\alpha$ in peritoneal lavage fluid and intestinal tissue. The tissue was thawed, rinsed, wiped dry by clean filter paper, and ground into homogenates. Homoegenates were centrifuged at $1,300 \times \mathrm{g}$ for $6 \mathrm{~min}$ at $4^{\circ} \mathrm{C}$ to harvest the supernatant. ELISA kit was used for detection of IL-1 $\beta$, IL- 6 and TNF- $\alpha$ concentration, strictly according to the instructions. Rat IL-1 $\beta$ ELISA kit (cat. no. 69-30375); rat IL-6 ELISA kit (cat. no. 69-30490) and rat TNF- $\alpha$ ELISA kit (cat. no. 69-25328) were purchased from Moshake Biotechnology Company (Wuhan, China; http://www.mskbio. com/index.aspx). Standard curve was made to calculate the concentration of IL-1 $\beta$, IL- 6 and TNF- $\alpha$.

Western blotting detection of TLR-4, ICAM-1 and VCAM-1 expression in intestinal tissue. Intestinal tissue protein samples were centrifuged at $10,000 \mathrm{xg}$ for $5 \mathrm{~min}$ at $4^{\circ} \mathrm{C}$ and the supernatant was taken for electrophoresis. The sample volume was adjusted to equal amount according to the protein concentration by using the E-PAGE ${ }^{\mathrm{TM}}$ loading buffer (cat. no. EPBUF01; Thermo Fisher Scientific, Inc., Waltham, MA, USA). Proteins $(30 \mu \mathrm{g})$ were added into per lane for the electrophoresis. The extracted proteins were separated using a $10 \%$ sodium dodecyl sulphate-polyacrylamide gel electrophoresis (SDS-PAGE).
After electrophoresis, the separated protein was transferred to the polyvinylidene fluo-ride (PVDF) membrane by $250 \mathrm{~mA}$ constant flow membrane. Then the membrane was incubated for $2 \mathrm{~h}$ in Tris-buffered saline-tween (TBST) containing $5 \%$ skimmed milk for blocking. The primary antibody was diluted with TBST and added to protein samples for overnight incubation at $4^{\circ} \mathrm{C}$ in a refrigerator. The samples were then incubated with peroxidase labelled secondary antibody at room temperature for $2 \mathrm{~h}$. The UVP chemiluminescence imaging system was used for continuous collection of images. Rabbit polyclonal TLR4 antibody (cat. no. ab13556; dilution, 1:500); rabbit monoclonal ICAM1 antibody (cat. no. ab53013; dilution, 1:500); rabbit monoclonal VCAM1 antibody (cat. no. ab134047; dilution, 1:500); rabbit polyclonal NF-kB p65 antibody (cat. no. ab16502; dilution, 1:500); rabbit monoclonal IKB alpha antibody (cat. no. ab32518; dilution, 1:500); rabbit polyclonal GAPDH antibody (cat. no. ab37168; dilution: 1:500) and secondary goat anti-rabbit (HRP) IgG antibody (cat. no. ab6721; dilution, 1:2,000) were all purchased from Abcam (Cambridge, MA, USA). The images were semi-quantitative analyzed with the light density value of target protein/ GAPDH. The gray value was analyzed using ImageJ software (Version 1.38; National Institutes of Health, Bethesda, MA, USA).

Statistical analysis. SPSS19.0 (IBM Corp., Armonk, NY, USA) software was used for statistical analysis. The measurement data are presented as mean \pm standard deviation (SD). Comparison between groups was done using one-way ANOVA test followed by post-hoc test (Least Significant Difference). $\mathrm{P}<0.05$ was considered to indicate a statistically significant difference.

\section{Results}

Establishment of septic shock rat model. Generally, septic shock CLP model in rats was duplicated successfully in $16-23 \mathrm{~h}$. After $14.5 \mathrm{~h}$ replication of model, the MAP of rats was monitored. At 14.5-15 h, there was no significant difference in MAP between groups. At $15.5 \mathrm{~h}$, the MAP of the rats in the septic shock group was lower than that of the blank control group $(\mathrm{P}<0.05)$, but it did not reach $70 \%$ of the control group MAP. At $16 \mathrm{~h}$, when compared with the control group, MAP of the other 2 groups was significantly decreased (Fig. 1), down to $70 \%$ of the blank control group, indicating that the model of septic shock rat model was successfully established. In the blank group, the cultured blood was bacteria negative, while the cultured blood of the other 2 groups were found to be Escherichia coli (+). Moreover, in the blank group, the bacterial culture of the peritoneal lavage fluid was negative, whereas the other 4 groups were found to be Escherichia coli (+), with other heterozygous bacteria.

Increased expression of $I L-1 \beta, I L-6$ and TNF- $\alpha$ in abdominal lavage fluid and intestinal tissue in rats with septic shock. The RPMI-1640 culture medium was used to wash the abdominal cavity of rats in each group, and the peritoneal lavage fluid was taken respectively with the supernatant removed by centrifugation at $2,000 \mathrm{xg}$ for $3 \mathrm{~min}$ at $4^{\circ} \mathrm{C}$. The concentration of IL-1 $\beta$, IL- 6 and TNF- $\alpha$ in each group of lavage liquid 

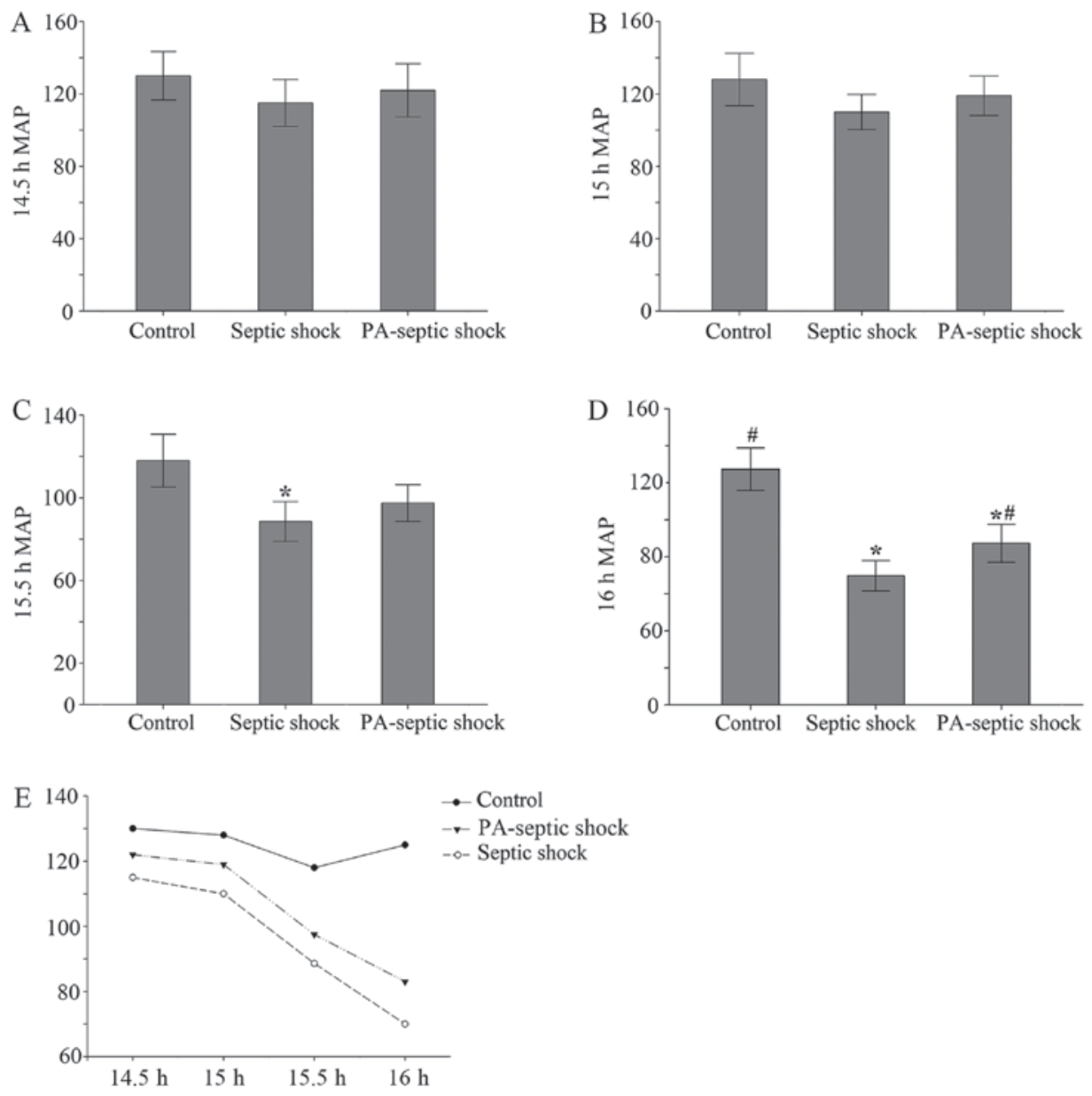

Figure 1. Changes in average arterial pressure in each treatment group. (A and B) There was no significant difference in MAP between 14.5-15 $\mathrm{h}$ rats after the establishment of the model. (C) After $15.5 \mathrm{~h}$ the model was established, compared with the blank control group, the MAP of the rats in the septic shock group decreased $(\mathrm{P}<0.05)$, PA-infection shock group had no significant changes. (D) Compared with the blank group, the MAP in the other 2 groups decreased significantly, and compared with the septic shock group, the mean arterial pressure in the PA-septic shock group increased. (E) The MAP of the rats in the septic shock group and the PA-septic shock group showed a progressive decline, and the MAP in the blank control group did not change obviously. MAP, mean arterial pressure; PA, Pseudomonas aeruginosa. ${ }^{*} \mathrm{P}<0.05$, the difference between the control group and the blank control group was statistically significant. ${ }^{\text {"}} \mathrm{P}<0.05$, the difference was statistically significant compared with that of the septic shock group.
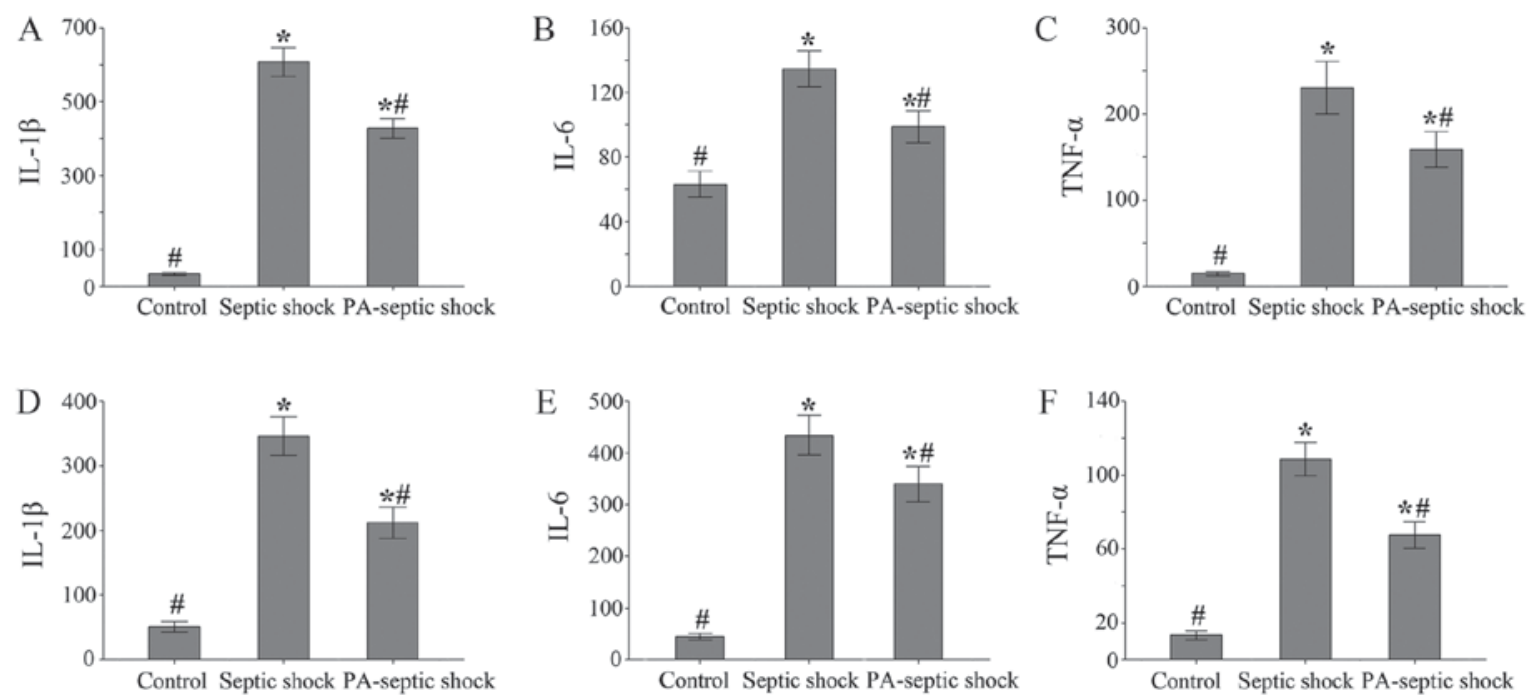

Figure 2. The concentration of inflammatory factors in the peritoneal lavage and intestinal tissue of each treatment group. (A-C) Compared with the blank control group, the concentration of IL-1, IL-6 and TNF- $\alpha$ in the other 2 groups of peritoneal lavage fluid increased $(\mathrm{P}<0.05)$. Among them, the infection shock group was higher than the PA-septic shock group ( $\mathrm{P}<0.05)$. (D-F) Compared with the blank control group, the concentration of IL-1, IL-6 and TNF- $\alpha$ in the intestinal homogenate of the septic shock group and the PA-septic shock group increased. IL-1, interleukin-1; TNF- $\alpha$, tumor necrosis factor- $\alpha$; PA, Pseudomonas aeruginosa. ${ }^{*} \mathrm{P}<0.05$, the difference between the control group and the blank control group was statistically significant. ${ }^{\#} \mathrm{P}<0.05$, the difference was statistically significant compared with that of the septic shock group. 
A

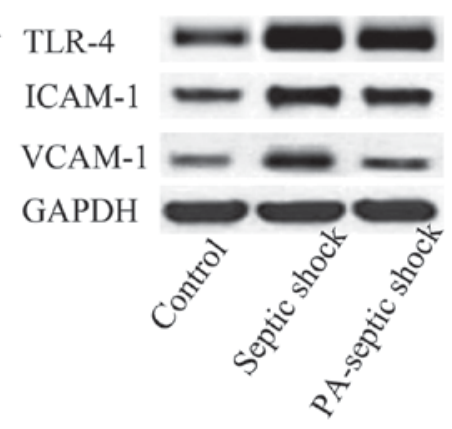

$\mathrm{C}$

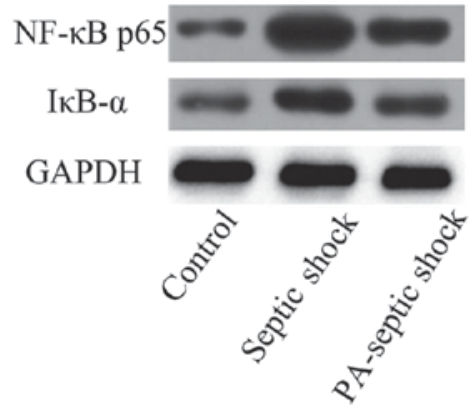

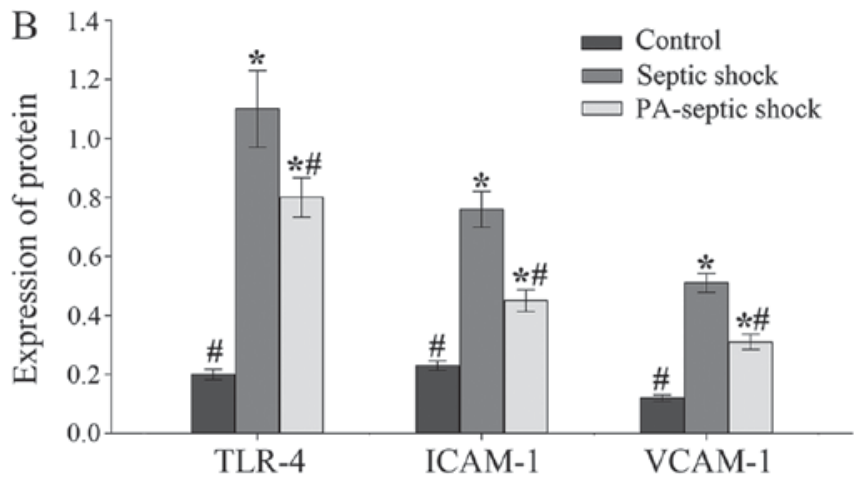

$\mathrm{D}$

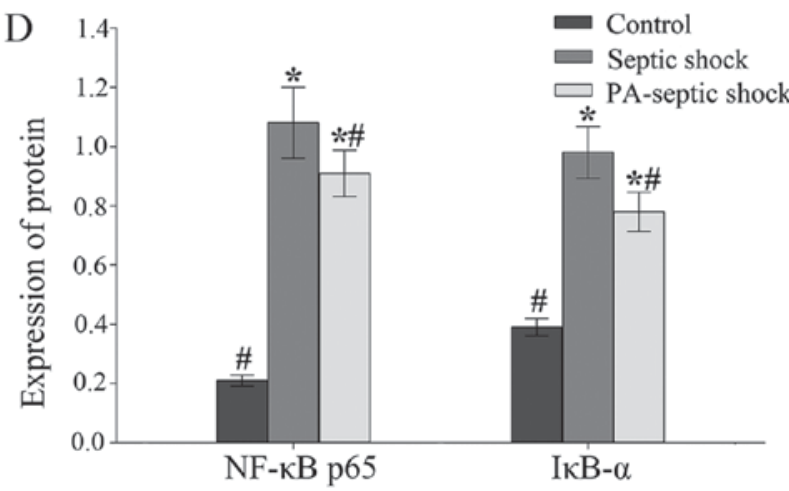

Figure 3. The expression level of TLR-4 NF- $\mathrm{B}$ pathway protein, ICAM-1 and VCAM-1 in the intestinal tissue of each treatment group. (A and B) Compared with the blank control group, the expression of TLR-4, ICAM-1 and VCAM-1 in the intestinal tissue of the septic shock group and the PA-septic shock group increased $(\mathrm{P}<0.05)$. The expression level of the septic shock group was higher than that of the $\mathrm{PA}$-septic shock group $(\mathrm{P}<0.05)$. $(\mathrm{C}$ and $\mathrm{D}) \mathrm{Compared}$ with

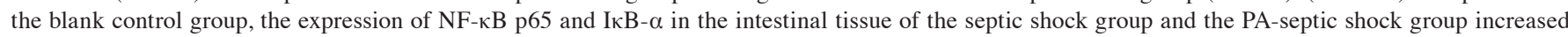
$(\mathrm{P}<0.05)$. The expression level of the septic shock group was higher than that of the PA-septic shock group (P<0.05). TLR, toll like receptor; PA, Pseudomonas aeruginosa. ${ }^{*} \mathrm{P}<0.05$, the difference between the control group and the blank control group was statistically significant. ${ }^{\#} \mathrm{P}<0.05$, the difference was statistically significant compared with that of the septic shock group.

was detected by ELISA kit. The results showed that compared with the blank control group, the concentrations of IL-1 $\beta$, IL-6 and TNF- $\alpha$ in peritoneal lavage fluid of septic shock group and PA-septic shock group were both increased $(\mathrm{P}<0.05)$. Among them, the concentrations of IL-1 $\beta$, IL- 6 and TNF- $\alpha$ in septic shock group was higher than the PA-septic shock group $(\mathrm{P}<0.05)$ (Fig. 2A-C).

Furthermore, compared with the blank control group, the concentrations of IL-1 $\beta$, IL- 6 and TNF- $\alpha$ in the intestinal homogenate of both septic shock group and PA-septic shock group increased $(\mathrm{P}<0.05)$ (Fig. 2D-F).

Expression of TLR-4-NF- $\mathrm{B}$, ICAM-1 and VCAM-1 in intestinal tissue of septic shock rats increased significantly. The expression of related proteins in the intestinal tissue of rats was detected by western blotting. The results showed that compared with the blank control group, the expression of TLR-4-NF- $\kappa$ B and ICAM-1 and VCAM-1 in the intestinal tissue of septic shock group and PA-infected shock group increased $(\mathrm{P}<0.05)$, and the expression level of the septic shock group was higher than that of the PA-septic shock group $(\mathrm{P}<0.05)$ (Fig. 3).

The positive rate of TLR-4 expression on the surface of peripheral blood neutrophils and the number of chemotaxis neutrophils in the peripheral blood of rats with septic shock were significantly increased. Neutrophils were isolated from peripheral blood and the positive rate of TLR4 expression in neutrophils was detected by flow cytometry. The positive rate of TLR-4 expression in peripheral blood of septic shock group and PA-septic shock group was significantly higher than that in blank control group $(\mathrm{P}<0.05)$ (Fig. 4A). Additionally, the number of chemotaxis neutrophils in peripheral blood of each group was detected by Transwell chamber method. It was found that the number of chemotaxised neutrophils in the peripheral blood of the septic shock group was fewer than that of the PA-septic shock group $(\mathrm{P}<0.05)$ (Fig. 4B-E).

\section{Discussion}

In recent years, immunomodulatory therapy has become a new direction for the treatment of sepsis. From the perspective of pathogenic biology, sepsis is potentially a life-threatening complication of infection, which is initiated by pathogen endotoxin release to blood circulation (21). It is a complex, dynamic syndrome with great heterogeneity related to ethnic, sex, age, genetic and environmental factors (22). Innate immunity is the first line of defense against pathogenic microorganism infection. The innate immune system specifically recognizes PAMPs by pathogen 
A
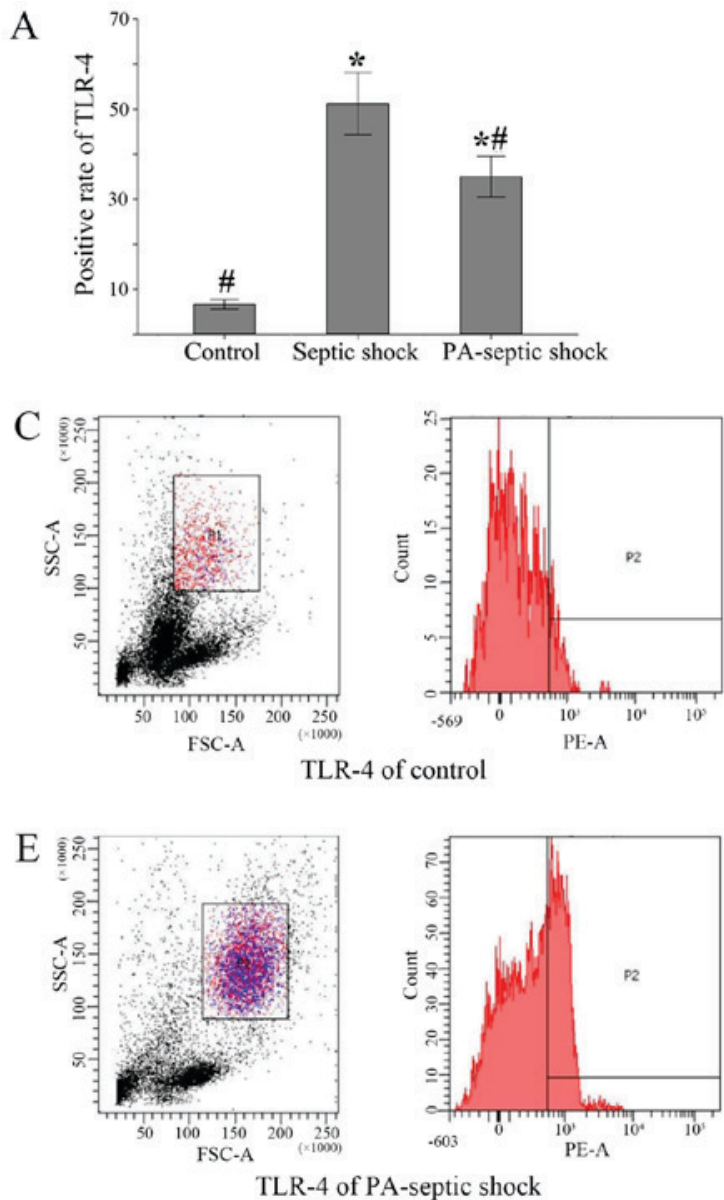

$\mathrm{B}$
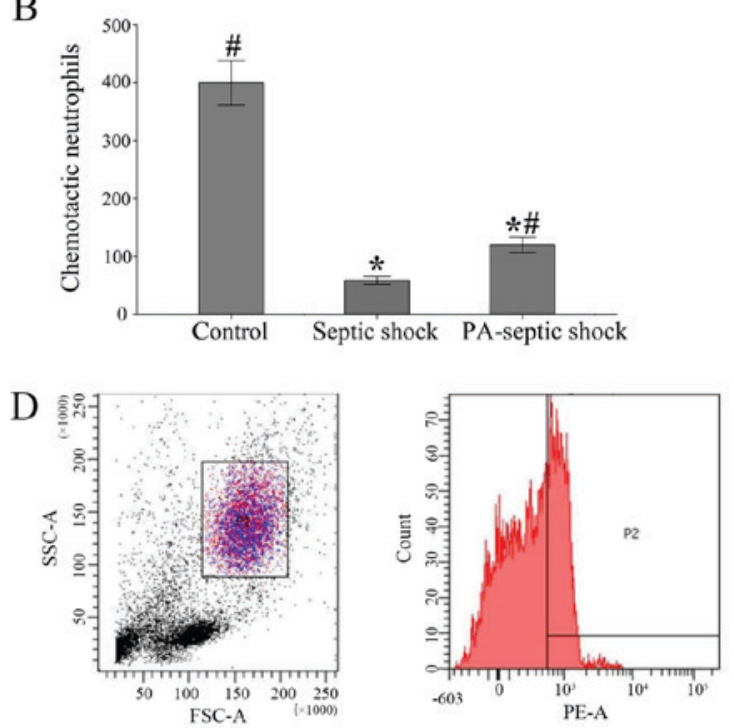

TLR-4 of septic shock

Figure 4. TLR-4 positive rate of neutrophils in peripheral blood and the number of chemokine in vitro. (A) Compared with the blank control group, the expression TLR-4 of neutrophil in peripheral blood of the septic shock group and PA-septic shock group increased significantly (P<0.05). (B) Compared with the blank group, the number of chemotaxis of neutrophil in peripheral blood of septic shock group and PA-infected shock group decreased (P<0.05), and the number of septic shock group was less than that of PA-infection shock group $(\mathrm{P}<0.05)$. (C) TLR-4 expression of neutrophils in control group was detected by flow cytometry. (D) TLR-4 expression of neutrophils in septic shock group was detected by flow cytometry. (E) TLR-4 expression of neutrophils in PA-infected shock group was detected by flow cytometry. TLR, toll like receptor; PA, Pseudomonas aeruginosa. *P $<0.05$, the difference between the control group and the blank control group was statistically significant. "P<0.05, the difference was statistically significant compared with that of the septic shock group.

recognition receptors (PPRs), thus effectively initiating the immune response. As a member of the PPRs family, the TLR is one of the most important receptors in the innate immune system. TLR-4 is the first TLR recognized by researches, they are mainly expressed in the cells involved in host defense functions, such as macrophages, neutrophils, dendritic cells, lymphocytes, endothelial cells and epithelial cells. Renal tubular epithelial cells, heart, respiratory epithelial cells and intestinal epithelial cells also express TLR-4 (23-25).

Because of its important role in the initial stage of inflammation, TLR-4 has become a potential target for the treatment of septic shock. It is known that TLR4 can mediate the recognition of lipopolysaccharide (LPS) by identifying the characteristic PAMPs in the outer membrane of gram negative bacteria, which is an important trigger of inflammatory response in septic shock (26). In addition to LPS, various endogenous ligands can be identified by TLR-4, such as HMGB1 (27). TLR-4 can activate the transcription factors, such as NF- $\kappa$ B, MCP-1, ICAM-1, and other inflammatory factors through the MyD88-dependent signaling pathway (28). In recent studies, blocking the expression of the TLR4-MD2 complex can prevent septic shock (29).
PA-MSHA can enhance the immune defense, while on the one hand, the cellular component of PA-MSHA can activate PPRs such as TLR-4. As a result, PA-MSHA can activate a variety of immune cells, such as dendritic cells, macrophages, Treg and NK cells, as well as help reconstruct the immune surveillance and immune defense (30). Furthermore, PA-MSHA has immunogenicity, which can regulate the activation of polyclonal B cells and produce broad-spectrum, highly effective bactericidal antibodies. It can effectively defend against the infection caused by gram-negative bacilli (31).

The aim of this research is to observe the expression of cytokines, TLR-4, adhesion molecules and the expression of TLR4 on peripheral blood neutrophils in septic shock rats after PA-MSHA pretreatment.

The results showed in our rat sepsis model, that the expression of TLR4 in the intestinal tissue, as well as the rate of TLR-4 positive cells in the peripheral blood neutrophils were significantly higher than that in the blank group. PA-MASH pretreatment could reduce the expression level of TLR-4 in intestinal tissue and the TLR-4 positive neutrophils in the intestinal tissue of rats with septic shock. At the same time, the concentration of inflammatory factors IL-1 $\beta$, IL-6 and TNF- $\alpha$ 
in the abdominal and intestinal tissues of each group also showed the same trend. This suggested that PA-MSHA can reduce the expression of TLR-4 receptor, inhibit TLR4-NF- $\mathrm{B}$ proinflammatory factor pathway and suppress the release of proinflammatory factors, thereby effectively inhibiting inflammatory reaction and reducing intestinal mucosal injury in rats.

ICAM-1 and VCAM-1 are important adhesion molecules that mediate cell adhesion. ICAM-1 and VCAM-1 belong to the immunoglobulin superfamily, which act as the ligands of leukocyte adhesion molecule integrin, and play a key role in the process of the late stage of adherence of leukocytes to endothelial cells and migration of endothelial cells (32-34). Their main role is to stabilize intercellular interactions and to promote adherence of inflammatory cells and endothelial cells (35). When inflammatory reaction occurs, with the action of LPS and cytokines such as IL-1, TNF- $\alpha$, INF- $\gamma$, ICAM-1 was activated on the cell surface especially in endothelial cells. VCAM-1 activates endothelial cell NADPH oxidase and shrinks endothelial cells. The opened 'endothelial cell gate' is an important channel for inflammatory cells to migrate from blood to tissue (36).

In this study, the expression levels of ICAM-1 and VCAM-1 in other two groups were both higher than that in the blank group. When the septic shock occurs, a large number of inflammatory mediators are released into the blood, which can promote the migration of inflammatory cells to the infected site by upregulating the expression level of ICAM-1 and VCAM-1. On the other hand, ICAM-1 can further increase the expression of VCAM-1, which promote inflammatory cells to release more inflammatory mediators. In addition, inflammatory mediators further exacerbate excessive ischemia-reperfusion injury, aggravate the damage of intestinal mucosal barrier function, thereby leading to more pathogenic bacteria and endotoxin entering into the blood. Eventually, vicious spiral was formed to accelerate the progression of septic shock. Furthermore, our study also demonstrated that the expression levels of ICAM-1 and VCAM-1 in septic shock group were both higher than those in PA- infected shock group, indicating that PA-MSHA premedication could inhibit the expression of ICAM-1 and VCAM-1 in intestinal tract of rats with septic shock. It is hypothesized that PA-MSHA can reduce the expression of TLR-4 and further inhibit the TLR4-NF- $\kappa$ B-proinflammatory pathway; As a result, the release of proinflammatory factors was suppressed, thereby effectively inhibiting the inflammatory response and reducing the intestinal mucosal injury in rats. Some studies have shown that LPS induces the production of ROS by activating the 'TLR4/MyD88/c-Src/NADPH oxidase' pathway and triggers the activation of p38MAPK and ATF2. Activated ATF2 can lead to an increase in VCAM-1 promoter activity and increase the expression of VCAM-1 (37). Other studies have shown that LPS can increase the production of ROS by activating TLR4/MyD88/TRAF6/c-Src/NADPH oxidase pathway, and then activate NF- $\kappa \mathrm{B}$, which leads to the increase of ICAM-1 production (38).

In conclusion, PA-MSHA pretreatment can reduce the systemic and local (intraperitoneal, intestinal) inflammation, thus preventing the intestinal injury caused by septic shock. Our results indicated that the underlying mechanisms might include that PA-MSHA suppressed TLR4-NF- $\kappa$ B-proinflammatory pathway and inhibited the role of adhesion molecules such as ICAM-1 and VCAM-1. Our study offers new insight into the future therapy of septic shock.

\section{Acknowledgements}

Not applicable.

\section{Funding}

This work was supported in part by grants from the National Natural Science Foundation of China (no. 81701881), and the Nanjing Medical Science and Technology Development Foundation (no. YKK17102).

\section{Availability of data and materials}

All data generated or analyzed during this study are included in this published article.

\section{Authors' contributions}

WZ and XW designed the study and performed the experiments, JS, XS and YX established the animal models, JS and SY collected the data, WZ and JS analyzed the data, WZ and XW prepared the manuscript. All authors read and approved the final study.

\section{Ethics approval and consent to participate}

This study was approved by the Animal Ethics Committee of Nanjing First Hospital, Nanjing Medical University Animal Center (Nanjing, China).

\section{Patient consent for publication}

Not applicable.

\section{Competing interests}

The authors declare that they have no competing interests.

\section{References}

1. Ferrer R, Martin-Loeches I, Phillips G, Osborn TM, Townsend S, Dellinger RP, Artigas A, Schorr C and Levy MM: Empiric antibiotic treatment reduces mortality in severe sepsis and septic shock from the first hour: Results from a guidelinebased performance improvement program. Crit Care Med 42: 1749-1755, 2014.

2. Bassetti M,RighiE,AnsaldiF,MerelliM,TrucchiC,DePascale G, Diaz-Martin A, Luzzati R, Rosin C, Lagunes L, et al: A multicenter study of septic shock due to candidemia: Outcomes and predictors of mortality. Intensive Care Med 40: 839-845, 2014.

3. Bihari D, Prakash S and Bersten A: Low-dose vasopressin in addition to noradrenaline may lead to faster resolution of organ failure in patients with severe sepsis/septic shock. Anaesth Intensive Care 42: 671-674, 2014.

4. Greeneltch KM, Haudenschild CC, Keegan AD and Shi Y: The opioid antagonist naltrexone blocks acute endotoxic shock by inhibiting tumor necrosis factor-alpha production. Brain Behav Immun 18: 476-484, 2004.

5. Tidswell M and LaRosa SP: Toll-like receptor-4 antagonist eritoran tetrasodium for severe sepsis. Expert Rev Anti Infect Ther 9: 507-520, 2011. 
6. Bone RC, Balk RA, Cerra FB, Dellinger RP, Fein AM Knaus WA, Schein RM and Sibbald WJ; The ACCP/SCCM Consensus Conference Committee. American College of Chest Physicians/Society of Critical Care Medicine: Definitions for sepsis and organ failure and guidelines for the use of innovative therapies in sepsis. Chest 101: 1644-1655, 1992.

7. Rittirsch D, Flierl MA and Ward PA: Harmful molecular mechanisms in sepsis. Nat Rev Immunol 8: 776-787, 2008.

8. Hotchkiss RS and Nicholson DW: Apoptosis and caspases regulate death and inflammation in sepsis. Nat Rev Immunol 6 : 813-822, 2006

9. Solomkin JS, Jenkins MK, Nelson RD, Chenoweth D and Simmons RL: Neutrophil dysfunction in sepsis. II. Evidence for the role of complement activation products in cellular deactivation. Surgery 90: 319-327, 1981.

10. Witko-Sarsat V, Rieu P, Descamps-Latscha B, Lesavre P and Halbwachs-Mecarelli L: Neutrophils: Molecules, functions and pathophysiological aspects. Lab Invest 80: 617-653, 2000.

11. Luster AD: Chemokines - chemotactic cytokines that mediate inflammation. N Engl J Med 338: 436-445, 1998.

12. Liu Z, Lei X, Li X, Cai JM, Gao F and Yang YY: Toll-like receptors and radiation protection. Eur Rev Med Pharmacol Sci 22: 31-39, 2018

13. Zhang Y, Lu Y, Ma L, Cao X, Xiao J, Chen J, Jiao S, Gao Y, Liu C, Duan Z, et al: Activation of vascular endothelial growth factor receptor-3 in macrophages restrains TLR4-NF- $\kappa \mathrm{B}$ signaling and protects against endotoxin shock. Immunity 40: 501-514, 2014.

14. Castle NA: Aquaporins as targets for drug discovery. Drug Discov Today 10: 485-493, 2005.

15. Xu WH, Liu ZB, Hou YF, Hong Q, Hu DL and Shao ZM: Inhibition of autophagy enhances the cytotoxic effect of PA-MSHA in breast cancer. BMC Cancer 14: 273, 2014.

16. Li T, Dong ZR, Guo ZY, Wang CH, Zhi XT, Zhou JW, Li DK, Chen ZT, Chen ZQ and Hu SY: Mannose-mediated inhibitory effects of PA-MSHA on invasion and metastasis of hepatocellular carcinoma via EGFR/Akt/I $\kappa \mathrm{B} \beta / \mathrm{NF}-\kappa \mathrm{B}$ pathway. Liver Int 35: 1416-1429, 2015.

17. Hou J, Liu Y, Liu Y and Shao Y: The MSHA strain of Pseudomonas aeruginosa activated TLR pathway and enhanced HIV-1 DNA vaccine immunoreactivity. PLoS One 7: e47724, 2012.

18. Zhang M, Luo F, Zhang Y, Wang L, Lin W, Yang M, Hu D, Wu X and Chu Y: Pseudomonas aeruginosa mannose-sensitive hemagglutinin promotes T-cell response via toll-like receptor 4-mediated dendritic cells to slow tumor progression in mice. J Pharmacol Exp Ther 349: 279-287, 2014.

19. Liu XF, Wang L, Qu Y, Zhong DW, Miao XY and Yao HL: Effect of the PA-MSHA vaccine on septic serum-induced inflammatory response. Mol Med Rep 7: 1350-1354, 2013.

20. Wen H: Sepsis induced by cecal ligation and puncture. Methods Mol Biol 1031: 117-124, 2013.

21. Buras JA, Holzmann B and Sitkovsky M: Animal models of sepsis: Setting the stage. Nat Rev Drug Discov 4: 854-865, 2005.

22. Wiersinga WJ: Current insights in sepsis: From pathogenesis to new treatment targets. Curr Opin Crit Care 17: 480-486, 2011.

23. Kumar $\mathrm{H}$ and Bot $\mathrm{A}$ : Innate immune recognition mechanisms and translational opportunities. Int Rev Immunol 32: 113-115, 2013.

24. Kumar S, Ingle H, Prasad DV and Kumar H: Recognition of bacterial infection by innate immune sensors. Crit Rev Microbiol 39: 229-246, 2013

25. Bachar O, Adner M, Uddman R and Cardell LO: Toll-like receptor stimulation induces airway hyper-responsiveness to bradykinin, an effect mediated by JNK and NF-kappa B signaling pathways. Eur J Immunol 34: 1196-1207, 2004.
26. Poltorak A, He X, Smirnova I, Liu MY, Van Huffel C, Du X, Birdwell D, Alejos E, Silva M, Galanos C, et al: Defective LPS signaling in $\mathrm{C} 3 \mathrm{H} / \mathrm{HeJ}$ and $\mathrm{C} 57 \mathrm{BL} / 10 \mathrm{ScCr}$ mice: Mutations in Tlr4 gene. Science 282: 2085-2088, 1998.

27. Park JS, Svetkauskaite D, He Q, Kim JY, Strassheim D, Ishizaka A and Abraham E: Involvement of toll-like receptors 2 and 4 in cellular activation by high mobility group box 1 protein. J Biol Chem 279: 7370-7377, 2004.

28. Kerger BD, Thuett KA and Finley BL: Evaluation of four $\alpha$-diketones for toll-like receptor-4 (TLR-4) activation in a human transfected cell line. Food Chem Toxicol 74: 117-119, 2014.

29. Daubeuf B, Mathison J, Spiller S, Hugues S, Herren S, Ferlin W, Kosco-Vilbois M, Wagner H, Kirschning CJ, Ulevitch R, et al: TLR4/MD-2 monoclonal antibody therapy affords protection in experimental models of septic shock. J Immunol 179: 6107-6114, 2007.

30. Levy MM, Fink MP, Marshall JC, Abraham E, Angus D, Cook D, Cohen J, Opal SM, Vincent JL and Ramsay G; International Sepsis Definitions Conference: 2001 SCCM/ESICM/ACCP/ATS/SIS international sepsis definitions conference. Intensive Care Med 29: 530-538, 2003.

31. Mossman KL, Mian MF, Lauzon NM, Gyles CL, Lichty B, Mackenzie R, Gill N and Ashkar AA: Cutting edge: FimH adhesin of type 1 fimbriae is a novel TLR4 ligand. J Immunol 181: 6702-6706, 2008

32. Nakae H, Endo S, Yamada Y and Inada K: Bound and soluble adhesion molecule and cytokine levels in patients with severe burns. Burns 26: 139-144, 2000.

33. Huang Q, Shao L, He M, Chen H, Liu D, Luo Y and Dai Y: Inhibitory effects of sasanquasaponin on over-expression of ICAM-1 and on enhancement of capillary permeability induced by burns in rats. Burns 31: 637-642, 2005.

34. Jersmann HP, Hii CS, Ferrante JV and Ferrante A: Bacterial lipopolysaccharide and tumor necrosis factor alpha synergistically increase expression of human endothelial adhesion molecules through activation of NF-kappaB and p38 mitogen-activated protein kinase signaling pathways. Infect Immun 69: 1273-1279, 2001.

35. Thomson AJ, Greer MR, Young A, Boswell F, Telfer JF, Cameron IT, Norman JE and Campbell S: Expression of intercellular adhesion molecules ICAM-1 and ICAM-2 in human endometrium: Regulation by interferon-gamma. Mol Hum Reprod 5: 64-70, 1999

36. Cook-Mills JM: VCAM-1 signals during lymphocyte migration: Role of reactive oxygen species. Mol Immunol 39: 499-508, 2002.

37. Lee IT, Shih RH, Lin CC, Chen JT and Yang CM: Role of TLR4/NADPH oxidase/ROS-activated p38 MAPK in VCAM-1 expression induced by lipopolysaccharide in human renal mesangial cells. Cell Commun Signal 10: 33, 2012.

38. Cho RL, Yang CC, Lee IT, Lin CC, Chi PL, Hsiao LD and Yang CM: Lipopolysaccharide induces ICAM-1 expression via a c-Src/NADPH oxidase/ROS-dependent NF- $\kappa \mathrm{B}$ pathway in human pulmonary alveolar epithelial cells. Am J Physiol Lung Cell Mol Physiol 310: L639-L657, 2016.

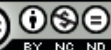

This work is licensed under a Creative Commons Attribution-NonCommercial-NoDerivatives 4.0 International (CC BY-NC-ND 4.0) License. 